\title{
Correlation Between the Kinematic Parameters Situation the Free Kick of Elite Players
}

\author{
Dujaka Aziz ${ }^{*}$, Sokoli Bylbyl \\ Faculty of Physical Education and Sport, University "Hasan Prishtina”, Pristina, Kosovo
}

\section{Email address:}

aziz.dujaka@uni-pr.edu (D. Aziz)

${ }^{*}$ Corresponding author

\section{To cite this article:}

Dujaka Aziz, Sokoli Bylbyl. Correlation Between the Kinematic Parameters Situation the Free Kick of Elite Players. American Journal of Sports Science. Vol. 7, No. 3, 2019, pp. 103-110. doi: 10.11648/j.ajss.20190703.14

Received: July 7, 2019; Accepted: July 26, 2019; Published: August 10, 2019

\begin{abstract}
This research is aimed at reviewing the correlation of seven situational kinematics parameters of the free kick of the elite soccer players (Cristiano Ronaldo): Angle of approach, Distance of free kick to the middle of the goal, Distance of the ball approach, Number of steps of ball approach, Length of the last step, Distance between the ball and the support leg, Angel inclination of the support leg. We used the cinematographical method through Kinovea- and Photo Suite 4, to 30 free kick videos -You Tube. Measurements of kinematics variables are measured directly in some frames to stages of movement, and after basic statistical analysis and Pearson's Correlation Coefficient (r). With six first variables we have analyzed the Approach phase where correlations significant positive relationships expressed variables Number of steps of ball approach - Ns with three other variables: Distance of the ball approach - Da, $r=0.431(\mathrm{p}=.020)$ and The length of the last step - Ls, $\mathrm{r}=0.397(\mathrm{p}$ $=.033)$ and Angle inclination of the support leg $-\phi, r=0.443(\mathrm{p}=0.018)$. as well as the variable Length of the last step $-\mathrm{Ls}$, which also has significant positive relations correlations with the variable Distance of the ball approach, running start $-\mathrm{Da}, \mathrm{r}=$ $0.745(\mathrm{p}=.000)$. Relationships between the off side and the free location and the angle of approach, the kicking in the same angle of the same side of approach have a value of about 30 degrees, and if it falls to the opposite angle of the opposite side, the angle of access has a value of about $50 \mathrm{deg}$.
\end{abstract}

Keywords: Instep Free Kick, Situational Kinematics Parameters, Angle of Approach, Distance the Goal, Running Start, Running Stride, Last Step, Inclination

\section{Introduction}

The variations of the ball kicks in the soccer sport are numerous, such as midway and wide distance kicks, goal collisions (penalty shootouts) as well as free kicking [1]. Particularly special are the free strikes, since they are executed by special positions, which distinguish the players who are specialists to score a goal from these positions. The goal scored by free kicks (from different positions and distances) is an indication of the high possession of the football technique. In elite football, there are a few players, one of whom is obviously Cristiano Ronaldo. The good biomechanical knowledge of football kicking (strikes) is very important in the process of technical acquisition with the young and in the process of perfection [1].

The aim of our study is the follow-up and correlation relations between the situations of kinematics parameters of soccer free kicking in the instep kick, footballer Cristiano Ronaldo, who has the highest percentage of achievement of the goals scored by the different positions of the port. The information that will be gained through this research will contribute to the development of the perfection of this kick in football, improving the learning process especially with young footballers.

\section{Methods}

\subsection{Subjects}

As we are dealing with an elite player such as Cristiano Ronaldo, who is known for the efficiency of goal scoring from different positions of free throws, we have selected his 
30 best free kicks since 2010 (Table 1), and we have made

biomechanical analysis at the footage that is on You Tube.

Table 1. A list of analyses free kick videos.

\begin{tabular}{|c|c|}
\hline 1. EPL, vs Portsmouth, 30/10/2008 & 16.EPL, vs Bolton, 19/03/2008 \\
\hline 2. Friendly, vs Europe XI, 13/03/2007 & 17.LaLiga, vs Ath.Madrid, 01/12/2012 \\
\hline 3. Friendly, vs Hertha Berlin, 23/07/2011 & 18.LaLiga, vs Calta Vigo, 05/ 03/2016 \\
\hline 4. UCL, vs Nicosia, $04 / 04 / 2012$ & 19.LaLiga, vs Villarreal, 15/05/2011 \\
\hline 5. EPL, vs Blackburn, 21/02/2009 & 20.EPL, vs Fulham, 04/02/2006 \\
\hline 6. UCL, vs Marseille, 08/12/2009 & 21.LaLiga, vs Sociedad, 09/11/2013 \\
\hline 7. LaLiga, vs Madrid, 11/04/2012 & 22.WC, vs Slovakia, 04/06/2005 \\
\hline 8. EURO-Quali, vs Denmark, 11/10.2011 & 23.UCL, vs Oly.Lyon, 02/11/2011 \\
\hline 9. LaLiga, vs Zaragoza, 12/12/2010 & 24.EPL, vs Stoke City, $15 / 11 / 2008$ \\
\hline 10. LaLiga, vs Villarreal, $21 / 02 / 2010$ & 25.UCL, vs Bayern, 29/04/2014 \\
\hline 11. UCL, vs Sp.Lisbon, 27/11/2007 & 26.LaLiga, vs Getafe, 25/03/2010 \\
\hline 12. LaLiga, vs Ath.Bilbao, 14/04/2013 & 27.Laliga, vs Getafe, $23 / 05 / 2015$ \\
\hline 13. EPL, vs Sunderland, $26 / 12 / 2007$ & 28.UCL, vs AC Milan, 19/10/2010 \\
\hline 14. UCL, vs Arsenal, 05/05/2009 & 29.EPL, vs Newcastle, $12 / 01 / 2008$ \\
\hline 15. UCl, vs Zurich, 25/11/2009 & 30.EURO-Quali, vs Bosna \& Herzegovina, 15/11/2011 \\
\hline
\end{tabular}

\subsection{Procedures}

The analysis of the free kicking phases is performed through Software Kinovea - Kinovea.Setup.0.8.15. exe and Kinovea-0.8.26-win32.exe,, where movie shooting is reproduced at a speed of 25 shots a second, in a time interval of $0.04 \mathrm{sec}$. between two frames (phase - frame), and processed with the Photo Suite 4 - Platinum Editor from MGI Software at:. This program allows us to increase or decrease the picture in order to save the real spatial dimensions from the fixed point, which in our case has represented the ball before the stroke.

The definition of spatial dimensions is realized through real space values - the caliber constant expressed by the diameter of the Soccer ball of size 5 which has the dimension $22-23 \mathrm{~cm}$.

\subsection{Variables}

The speed of the ball hit football depends on several factors: the speed of the foot before contact with the ball; body position at moment of ball kicking; duration of stroke and the angle of striking [2-4].

Our research includes 7 situational kinematic parameters based on the opportunities offered by the shooting of the 30 free kicks, a total of 210 measurements:

1. Angle of approach $(\alpha)$

2. Distance of free kick to the middle of the goal (Dg)

3. Distance of the ball approach (running start) (Da)

4. Number steps of ball approach (running stride) (Ns)

5. Length of the last step (Ls)

6. Distance between the ball and the support leg $(\mathrm{Db})$

7. Angle inclination of support leg $(\phi)$

\subsection{Statistical Analysis}

The statistical processing of the results (210) of this research involves the analysis of the 30 free-kicking, flowing kinematics parameters (7) and the obtained results are presented through the tables and graphs of the particular free kicking phases. For all measured variables, the basic statistical parameters are calculated (basic statistical - descriptive statistics), while for determining the relationships between the results variable correlations, they were subjected to the calculation of Pearson's Correlation Coefficient (r) using the IBM SPSS statistical system version 20 .

\section{Results}

\subsection{Angle of Approach - A (Degrees), (Tables 2, 3, 4)}

Approach represents several steps of running start that can be executed under a certain angle, closed, with the direction of the ball after the kick. The length of running start, the speed and the angle of approach are the most important aspects of this part of the preparation that have a significant impact on the soccer kick [5, 6]. Correlations of the low but not significant sensitivity of this variable are expressed with variable Length of the last step - Ls, of coefficient ( $\mathrm{r}=0.260)$, and with variable Distance of foot support of the ball - $\mathrm{Db}(\mathrm{r}=$ 0.222 ), while negative correlation with variable Distance to the middle of the goal - Dg $(\mathrm{r}=-0.157)$ (Table 4).

\subsection{Distance of Free Kick to the Middle of the Goal-Dg (Meters), (Tables 2, 3. 4)}

Light but not significant correlations this variable has with other variables Number steps of ball approach - Ns, $\mathrm{r}=$ 0.292, Angel inclination of support leg - $\phi(\mathrm{r}=0.277)$, Distance of the ball approach (running start) - Da, of coefficient $r=0.267$ (Table 4).

In Figure 3, it is noticed that the angle of the free throw space is almost from the middle of the gate to the left with an angle of approximately $45 \mathrm{deg}$. The free instep kick of the maximal distance (kicking 14) is $38 \mathrm{~m}$ to the right, while the one to the left (kick 4) is at a distance of $28 \mathrm{~m}$. The shortest kick, $19 \mathrm{~m}$ (kick 28), is opposite the middle of the gate.

\subsection{Distance of the Ball Approach (Running Start) - Da (Meters), (Tables 2, 3, 4)}

This distance (running stride), as seen in the example analyzed as a model for this work, (Graph 1), Cristiano Ronaldo passes $4 \mathrm{~m}$ distance, while from Table 2.-3 average 
distance of the ball approach is $4.355 \mathrm{~m}$. This variable has significant positive relationships correlations me variable Length of the last step $-\mathrm{Ls}, \mathrm{r}=0.745(\mathrm{p}=0.000)$, and variable Distance of the ball approach (running start) - Da, $\mathrm{r}=0.431$ $(\mathrm{p}=.020)$ and correlation with no significant difference with the variable Distance of free kick to the middle of the goal $\mathrm{Da}, \mathrm{r}=0.267$ (Table 4).

\subsection{Number Steps of Ball Approach (Running Stride) - Ns (Number), (Tables 2, 3, 4)}

The number of pitches to running strides according to [7], for executing the free kick with success is run up with 4 to 6 steps. The results of our study show that this variable has significant positive relationship correlations with variable $A n$ inclination of support leg $-\phi, \mathrm{r}=0.443(\mathrm{p}=.018)$, Distance of the ball approach (running start) - Da, $\mathrm{r}=0.431(\mathrm{p}=.020)$, Length of the last step - Ls, of coefficient $\mathrm{r}=0.397(\mathrm{p}=$ 0.033) (Table 4).

\subsection{Length of the Last Step - Ls (Meters), (Tables 2, 3, 4)}

During the run-in starting phase, the players do not aim at achieving the maximum speed, but the tendency is to do so by extending the last step of running starts with the aim of acting as efficiently as the ball hit, which [8], also propose.

This is also illustrated by the analysis of this step (running stride) of the sample analyzed as a sample for this work (Figure 1), length of the last step of Cristiano Ronaldo is 2.75 $\mathrm{m}$. Significant positive correlations relationships of variables Distance of the ball approach - Da, $\mathrm{r}=0.745(\mathrm{p}=.000)$, Number steps of ball approach $-\mathrm{Ns}, \mathrm{r}=0.397(\mathrm{p}=.033)$ (Table 4).

\subsection{Distance Foot of Support Leg to the Ball-Db (Meters),} (Tables 2, 3, 4)

Of the analyzed videos it is very difficult to determine this variable through calibration measure (diameter balls) so 30 free instep kicking are only 23 cases. According to [9], the non-kicking foot is a key element in the striking of the ball, although according to reports, they suggest that the placement of the support foot should be $5-10 \mathrm{~cm}$ on each side of the football $[9,10]$.

The light but not significant correlation of this variable is expressed by the variable Distance of the ball approach - Da, $\mathrm{r}=0.239$, with the variable Angle of approach $-\alpha, \mathrm{r}=-$ 0.222 , and variable Length of the last step - Ls, $r=0.211$ (Table 4).

\subsection{Angel Inclination of Support leg - $\phi$ (Degrees), (Tables 2, 3, 4)}

This kinematic parameter has been studied very little; although its role is discussed in certain works, especially for the last step of the free instep kick (Deceleration of the kicking leg during the follow-through) in order to maintain the balance of the body after executing free instep kick. This kinematic parameter is measured after kicking the ball between swing leg and ground of frontal plane.

This variable has a significant positive correlation relationship with the variable The number of steps of the ball approach $-\mathrm{Ns}, \mathrm{r}=0.443(\mathrm{p}=.018)$, and the correlation no significant difference with the variable with the variable Distance to the middle of the goal-Dg, $\mathrm{r}=0.277$, and the variable Distance of the ball approach - Da, $\mathrm{r}=0.204$ (Table 4).

Table 2. Kinematics situational parameters of analyzed free kick: 1. Angle of approach ( $\alpha$ ), 2. Distance of free kick to the middle of the goal (Dg), 3. Distance of the ball approach (running start) (Da), 4. Number steps of ball approach (running stride) (Ns), 5. Length of the last step (Ls), 6. Distance between the ball and the support leg (Db), 7. Angel inclination of support leg $(\phi)$.

\begin{tabular}{|c|c|c|c|c|c|c|c|}
\hline VARIABLES: & 1 & 2 & 3 & 4 & 5 & 6 & 7 \\
\hline Positions of free kicking & (a) deg. & (Dg) meter & (Da) meter & (Ns) namber & (Ls) meter & (Db) meter & (ф) deg. \\
\hline 1 & 15 & 27 & 7.0 & 3 & 3.0 & .17 & 48 \\
\hline 2 & 65 & 29 & 7.3 & 4 & 2.6 & .08 & 57 \\
\hline 3 & 15 & 28 & 4.3 & 3 & 1.7 & - & 56 \\
\hline 4 & 60 & 28 & 4.2 & 3 & 1.7 & .09 & 60 \\
\hline 5 & 35 & 25 & 4.1 & 3 & 1.6 & .15 & 55 \\
\hline 6 & 15 & 36 & 4.8 & 3 & 2.2 & .09 & 55 \\
\hline 7 & 35 & 33 & 3.4 & 3 & 1.6 & - & 52 \\
\hline 8 & 35 & 29 & 5.8 & 3 & 1.8 & .16 & 51 \\
\hline 9 & 20 & 26 & 4.1 & 3 & 1.7 & .12 & 52 \\
\hline 10 & 45 & 30 & 4.0 & 3 & 2.1 & - & 53 \\
\hline 11 & 45 & 28 & 4.8 & 3 & 1.9 & - & 56 \\
\hline 12 & 35 & 29 & 3.5 & 3 & 1.7 & .12 & 55 \\
\hline 13 & 50 & 24 & 3.8 & 3 & 1.8 & - & 50 \\
\hline 14 & 30 & 38 & 4.5 & 4 & 2.1 & .10 & 60 \\
\hline 15 & 30 & 25 & 3.7 & 3 & 1.8 & .08 & 56 \\
\hline 16 & 35 & 28 & 3.8 & 3 & 2.2 & .12 & 55 \\
\hline 17 & 40 & 28 & 4.8 & 3 & 1.9 & .06 & 52 \\
\hline
\end{tabular}




\begin{tabular}{|c|c|c|c|c|c|c|c|}
\hline VARIABLES: & 1 & 2 & 3 & 4 & 5 & 6 & 7 \\
\hline Positions of free kicking & (a) deg. & (Dg) meter & (Da) meter & (Ns) namber & (Ls) meter & (Db) meter & (ф) deg. \\
\hline 18 & 55 & 25 & 4.0 & 3 & 1.8 & .09 & 50 \\
\hline 19 & 30 & 27 & 3.8 & 3 & 1.6 & - & - \\
\hline 20 & 50 & 26 & 5.5 & 4 & 2.1 & .10 & 63 \\
\hline 21 & 65 & 27 & 4.2 & 3 & 1.9 & .11 & 46 \\
\hline 22 & 30 & 35 & 4.5 & 3 & 1.9 & .10 & 44 \\
\hline 23 & 20 & 19 & 3.5 & 3 & 1.8 & .08 & 53 \\
\hline 24 & - & 33 & - & - & - & - & - \\
\hline 25 & 30 & 21 & 3.5 & 3 & 1.9 & .08 & 45 \\
\hline 26 & 75 & 20 & 3.8 & 3 & 1.8 & .09 & 52 \\
\hline 27 & 60 & 30 & 4.2 & 4 & 2.1 & .12 & 50 \\
\hline 28 & 15 & 19 & 3.8 & 3 & 2.1 & .13 & 45 \\
\hline 29 & 75 & 21 & 3.5 & 3 & 1.7 & .12 & 47 \\
\hline 30 & 45 & 32 & 4.1 & 3 & 1.8 & .10 & 50 \\
\hline
\end{tabular}

Table 3. Basic statistical (Descriptive Statistics) parameters of specific variables derived from free kicking: VAR. 1. Angle of approach ( $\alpha$ ), VAR. 2. Distance of free kick to the middle of the goal (Dg), VAR. 3. Distance of the ball approach (running start) (Da), VAR. 4. Number steps of ball approach (running stride) (Ns), VAR. 5. Length of the last step (Ls), VAR. 6. Distance between the ball and the support leg (Db), VAR. 7. Angel inclination of support.leg ( $\phi)$.

\begin{tabular}{lllllllllll}
\hline & $\mathbf{N}$ & Minimum & Maximu & Mean & Std.Deviat & Variance & Skewness & \multicolumn{2}{c}{ Kurtosis } \\
\cline { 2 - 10 } & Statistic & Statistic & Statistic & Statis & Statistic & Statistic & Statisti & Std. Error & Statisti & Std. Error \\
\hline VAR 1 & 29 & 15 & 75 & 39.83 & 17.853 & 318.719 & .399 & .434 & -.671 & .845 \\
VAR 2 & 30 & 19 & 38 & 27.53 & 4.776 & 22.809 & .101 & .427 & -.053 & .833 \\
VAR 3 & 29 & 3.4 & 7.3 & 4.355 & .9642 & .930 & 1.890 & .434 & 3.512 & .845 \\
VAR 4 & 29 & 3 & 4 & 3.14 & .351 & .123 & 2.216 & .434 & 3.123 & .845 \\
VAR 5 & 29 & 1.6 & 3.0 & 1.928 & .3046 & .093 & 1.933 & .434 & 4.837 & .845 \\
VAR 6 & 23 & .06 & .17 & .1070 & .02738 & .001 & .728 & .481 & .254 & .935 \\
VAR 7 & 28 & 44 & 63 & 52.43 & 4.757 & 22.624 & .133 & .441 & -.255 & .858 \\
\hline
\end{tabular}

Table.4. Correlation coefficients of situational variables derived from free kicking: 1. VAR ( $\alpha$ ).-Angle of approach ( $\alpha)$, 2. VAR (Dg) - Distance of free kick to the middle of the goal (Dg), 3. VAR (Da) - Distance of the ball approach (running start) (Da), 4. VAR (Ns) - Number steps of ball approach (running stride) (Ns), 5. VAR (Ls) -Length of the last step (Ls), 6. VAR (Db) - Distance between the ball and the support leg (Db), 7. VAR ( $\phi)$ - Angel inclination of support leg $(\phi)$.

\begin{tabular}{llllllll}
\hline Variables: & $\mathbf{1}$ & $\mathbf{2}$ & $\mathbf{3}$ & $\mathbf{4}$ & $\mathbf{5}$ & $\mathbf{6}$ & $\mathbf{7}$ \\
\hline 1. VAR $(\alpha)$ & 1 & & & & & & \\
2. VAR $(\mathrm{Dg})$ & -.157 & 1 & & & & \\
3. VAR (Da) & .005 & .267 & 1 & & & \\
4. VAR (Ns) & .260 & .292 & $.431^{*}$ & 1 & 1 & \\
5. VAR (Ls) & -.111 & .164 & $.745^{* *}$ & $.397^{*}$ & 1 & \\
6. VAR (Db) & .222 & -.008 & .239 & -.119 & .211 & -.215 & 1 \\
7. VAR $(\phi)$ & .027 & .277 & .204 & $.443^{*}$ & -.002 & \\
\hline
\end{tabular}

* Correlation is significant at the 0.05 level (2-tailed).

** Correlation is significant at the 0.01 level (2-tailed).

\section{Discussion}

This approach phase defined the other phases, so the best knowledge of biomechanics of kicking can help in the training process. The trainer's experience in combination with the mechanical model of the desired performance implies the coach's need for a correct performance [11, 12].

\subsection{Angle of Approach - $\alpha$ (Degrees)}

In Table 3 shows that the average value of angle of approach for 29 analyzed kick, the value of mean is 39.84 deg. which can be said to be at the limit of the proposal of Lees et al [13], which proposes that this angle be from 30 to $45 \mathrm{deg}$ with the maximum ball to foot velocity achieved. This variable in the results of our work has correlation with no significant difference $(\mathrm{r}=-0.157)$ with variable Distance to the middle of to the goal - Dg (Table 4). Starting from the distance of free kick to the middle of the goal of $19 \mathrm{~m}$, the angle of approach is 17.5 degrees, while the distance $20-25$ $\mathrm{m}$ is $47 \mathrm{deg}$, distance $26-29 \mathrm{~m}$ is $39.23 \mathrm{deg}$, distance $30-38$ $\mathrm{m}$ is valued $37.14 \mathrm{deg}$. 


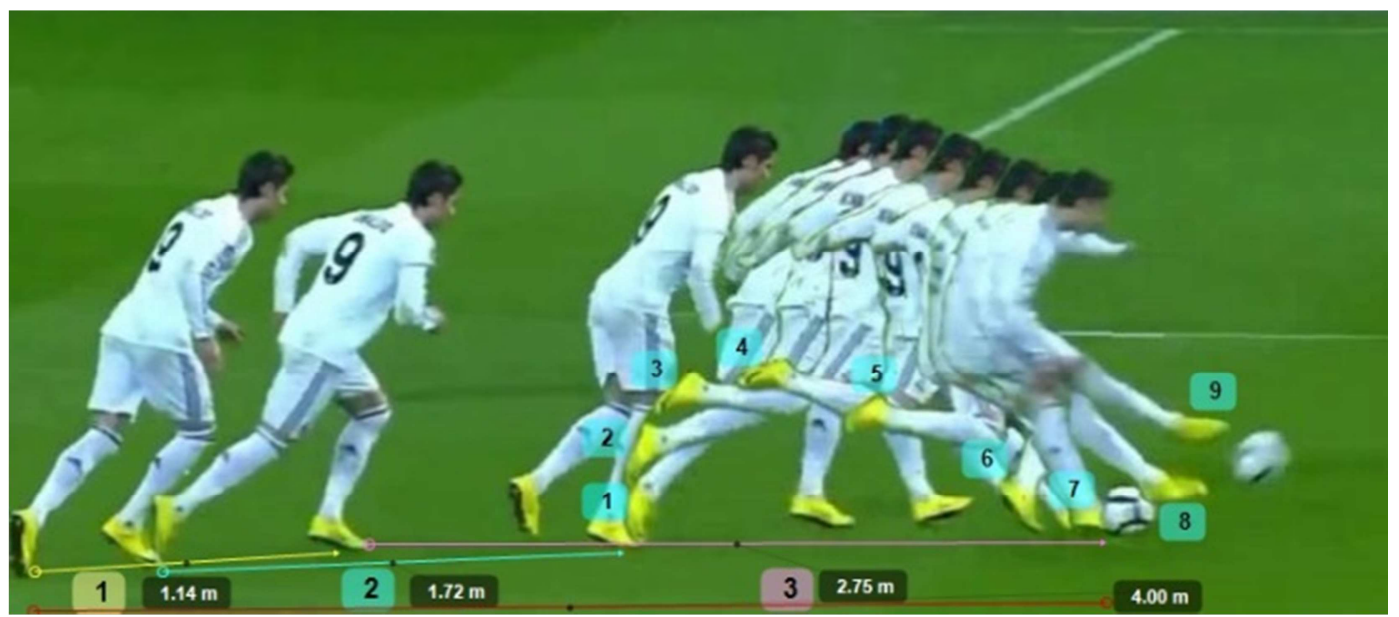

Figure 1. Kinogram of the free kicking phase, the whole movement (the running start - access to the ball, 4 meters), the first step $1.14 \mathrm{~m}$, second step $1.72 \mathrm{~m}$, and last step $2.75 \mathrm{~m}$.

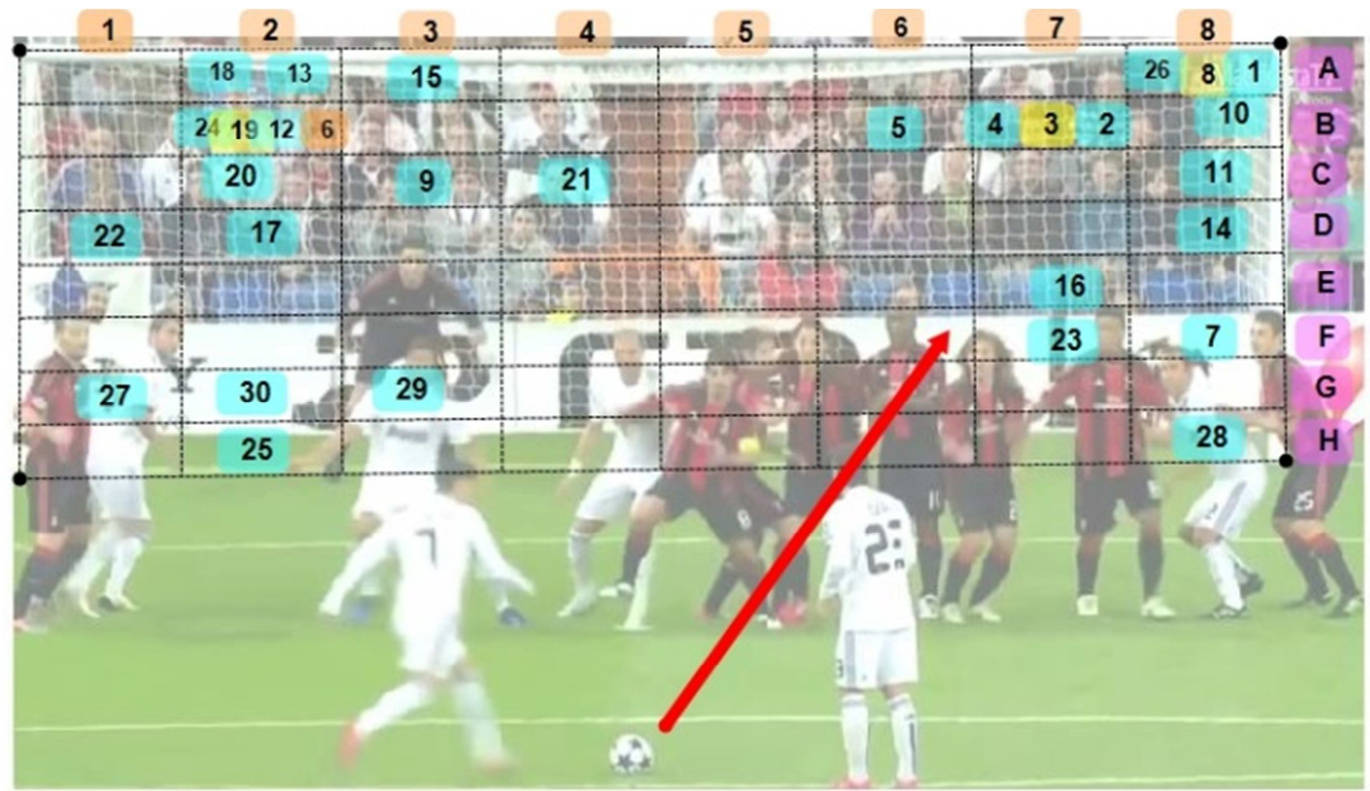

Figure 2. Accuracy in space ( $8 \times 8)$ to goal of free kicking.

\subsection{Distance of Free Kick to the Middle of the Goal - Dg (Meters)}

The most interesting results of the linkage of this variable distance of free kick to the middle of the goal and the angle of approach were obtained when we analyzed the location of the hit spot (Figure 3) with the place of goal scoring in port (Figure 2).

Right-sided positions (Table 2) of free-kicking positions, (positions 1, 2, 3) have a mean of $31.66 \mathrm{deg}$ of angle, while those kicks which have ended in the opposite angle (positions $13,17,18,20)$, on the left have mean of angle of approach $48.75 \mathrm{deg}$. The shootings executed from the left positions and that are fired in the corner of the gate of the same (positions $9,12,15,19,24)$ have mean of angle of approach $35 \mathrm{deg}$, while those shootings that have ended in the angle of opposite (positions 4, 5, 8, 10,11, 26), left have mean angle of approach 49, $16 \mathrm{deg}$. From this connection we can conclude for the players who execute the free-kick with right foot (as in our case Cristiano Ronaldo), it seems that if it is to hit the right corner of the goal from the kicking position from the right angle of approach is approximately $30 \mathrm{deg}$ (31.66), if the angle of approach is approximately $50 \mathrm{deg}$ (48.75), and if the left corner of the gate is to be kicked by the angle of approach, the angle of approach is approximately $35 \mathrm{deg}$, while the kicking in the angle of the opposite angle of approach is approximately $50 \mathrm{deg}$ (49.16). For further research, it remains to study the angle of approach depending on the placement of the living wall as the inevitable obstacle of free kicks. 


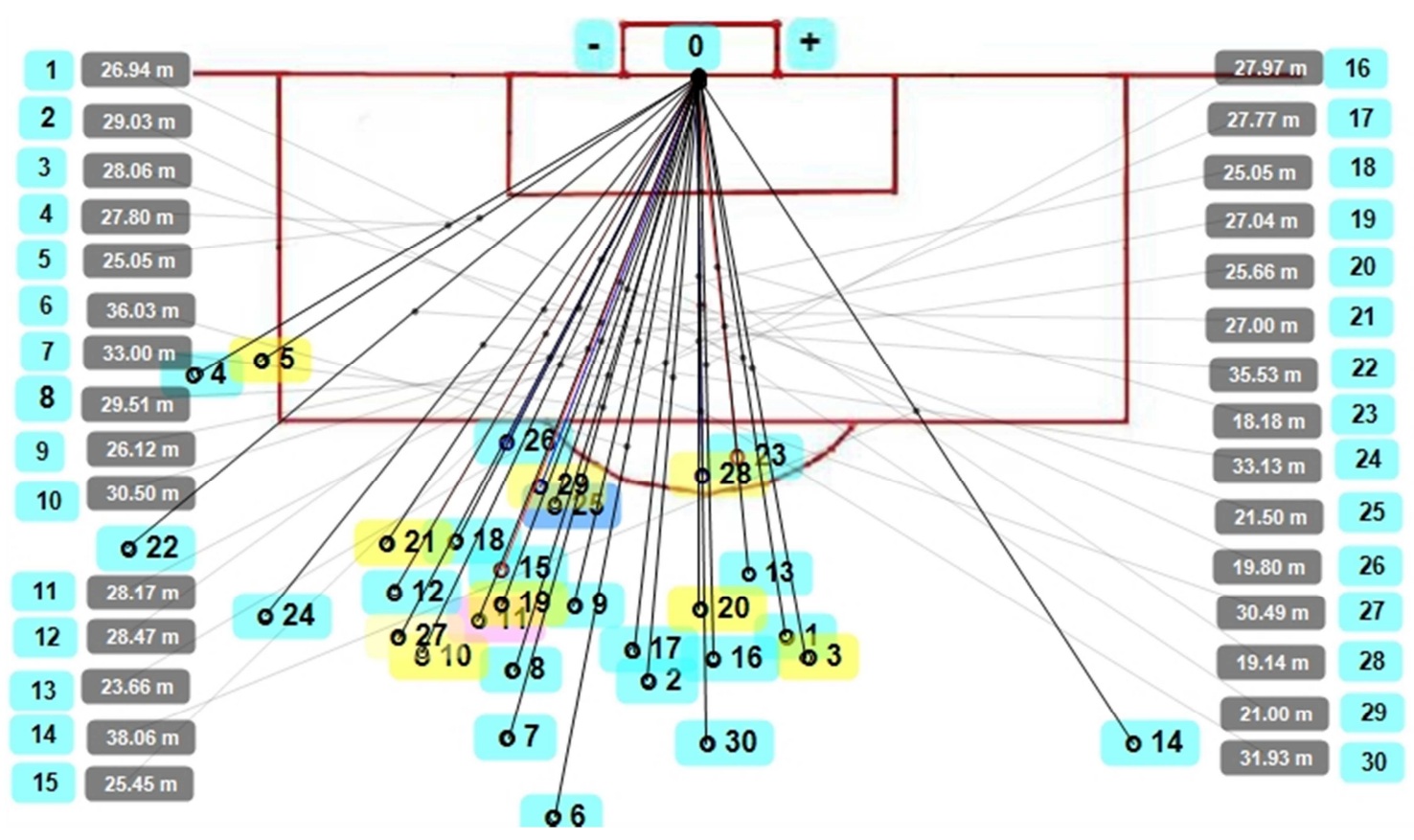

Figure 3. Linear distance from free kicking to midfield to goal.

\subsection{Distance of the Ball Approach (Running Start) - Da (Meters)}

From the results of our study to the variable distance of the ball approach that expresses the distance in meters of running start has a mean value $3.4 \mathrm{~m}$, where close to $90 \%$ of the results have a value of $3.409-5.334 \mathrm{~m}$. Although this distance of running start is aimed at achieving fast initial kick speeds, players get this speed $(100 \%)$ since the generation of ball-punch is created with the swing leg speed reached at the last step of running $(\mathrm{p}=.000)$, while correlation with variables number of steps of ball approach, $r=0.431(\mathrm{p}=$ 0.020 ) is logical since this variable lies within the distance of running start.

\subsection{Number Steps of Ball Approach (Running Stride) - Ns (Number)}

Kicking the ball with running start shows the top speed of the hit ball compared to the kick-off, but the difference between running start with one or more steps at the top speed is not confirmed, but practice has shown that soccer payers prefer running start with 2- 3 steps [14].

The number of steps for running stride is the values mean 3.14 step (3 - 4), which matches the results of the research of other authors. Correlation with the variables: Distance of the ball approach $-\mathrm{Da}, \mathrm{r}=0.431(\mathrm{p}=.020)$ and Length of the last step - Ls, $\mathrm{r}=0.397(\mathrm{p}=.033)$ as we said above is logical since this variable extends within the distance of running start. Correlation with variable Angle inclination of support leg $-\phi, r=0.443(\mathrm{p}=0.018)$ cannot be explained by the fact that there is no logical connection, except that numerical values during statistical processing have a small difference between maximum and minimum values 4 . Range $=1$ and 7 . Range $=19$ ).

\subsection{Length of the Last Step - Ls (Meters)}

During the approach phase, the force within the collision begins to form, which is carried in the last step and now with the added force acting at the foot of the swing leg [13], so the ball kick will be optimal [15] since it is possible to rotate the largest of the pelvic around the swing leg [16] by acting on the longer path foot of support leg to ball [8].

In the results of the study, the value of mean to length of the last step is $1,928 \mathrm{~m}$, while $93.10 \%$ of the results range from 1,624 to $2,232 \mathrm{~m}$. In the example analyzed as a footnote for this work (Graph 1), the length of the last step to Cristiano Ronaldo is $2.75 \mathrm{~m}$, while the step that precedes this is the length with small $(1.72 \mathrm{~m})$ but Cristiano Ronaldo passes in the last step of the jump without placing the ball in the ground, thereby significantly improving the "nailing" of foot to swing near the ball. The highest correlation of this variable $(\mathrm{r}=0.745, \mathrm{p}=0.01)$ with the variable (Distance of the ball approach -Da) is shown in the results of this work, the distance of the ball approach from 3.4 to $3.8 \mathrm{~m}$ (length of the last step is $1.75 \mathrm{~m})$, results $4.0-4.8 \mathrm{~m}(1.88 \mathrm{~m})$, results $5.0-5.8$ $\mathrm{m}(1.95 \mathrm{~m})$ and results $7.0-7.30 \mathrm{~m}(2.40 \mathrm{~m})$. The length of the last step has a different frequency of results at $1.80 \mathrm{~m} \mathrm{(7}$ times), $1.70 \mathrm{~m}$ (5 times), $1.90 \mathrm{~m}$ (5 times) and $2.10 \mathrm{~m}$ (5 times). Correlation with the variable Number of steps of ball approach - Ns, $\mathrm{r}=0.397(\mathrm{p}=.033)$ is stressed as we have to do with its results from 3 to 4 steps.

\subsection{Distance Between the Ball and the Support Leg-Db (Meters)}

According to the results of [17], the velocity of the ball depends primarily on the speed of the swing leg at the moment of contact with the ball and the position of the support leg when performing the kick. This is because of the 
high force impulse as well as because of the increase of the phases of compression and restitution of ball [18, 4, [19]. Kapidžić $[20]$ in their research found correlation $(r=-0.446)$ between the distance from the support leg to the ball (mean $14.13 \mathrm{~cm}$ ) and the speed of the ball (mean $20.95 \mathrm{~m} / \mathrm{s}$ ) of the Instep Kick in Youth Soccer Players. The results of our study for this variable have a value of mean $0.1070 \mathrm{~m}$ (min 0.06 and $\max 0.17 \mathrm{~m}$ ), while non-signatory correlation has the distance of running start $(r=0.239)$ and the length of the last step $(r=0.211)$ emerge as spatial distance, while negative correlation is also not significant with variable angle of approach $(r=-0.222)$. At the angle of approach $15-20 \mathrm{deg}$, value of means of variable distance between the ball and the support leg is $0.118 \mathrm{~cm}$, whereas at the angle of approach it is 30 - $35 \mathrm{deg}(0.113 \mathrm{~cm})$, angle of approach 40 - $55 \mathrm{deg}(0.112$ $\mathrm{cm})$, angle of approach $60-65 \mathrm{deg}(0.100 \mathrm{~cm})$.

\subsection{Angel Inclination of Support Leg - $\phi$ (Degrees)}

This parameter belongs to the last phase of the free instep kick in order to maintain the balance of the body after the execution of the kick and is measured after kicking the ball between the swing leg and the ground of the frontal plane, which in our study has the value of mean $52.48 \mathrm{deg}$. Although the inclination of the support leg is due to the dispersion of the kinetic and elastic forces formed by the swing leg [13], it is not the only form created to maintain the balance of the body. Thus, the upper part of the body provides the basal support of the pelvis (pelvic), tongs and arms, since the rotation of the pelvis is approximately 30 to $36 \mathrm{deg}$ with elite players $[8,21]$, while decreasing the distance between the swing leg and the opposite arms [13]. Our study results show that this variable has significant positive correlation relationships with variable Number steps of ball approach - Ns, $\mathrm{r}=0.443$ ( $\mathrm{p}=.018 \mathrm{even}$ though we are dealing with value of 3 and 4 steps. In total 28 of free instep kick which were analyzed, value of angel inclination of support leg results with higher frequencies is those of $50-56 \mathrm{deg}$ (20 times), 44-48 deg (6 times) and 58-63 (4-times). Correlation with no significant difference with the variable Distance to the middle of the goal - Dg $(r=0.277)$ is explained by the report where distance of the goal $19-21 \mathrm{~m}$ (value of mean is $48.4 \mathrm{deg}$ ), of distances $24-27 \mathrm{~m}$ (52.5 deg), of distances $28-30 \mathrm{~m}(55.8 \mathrm{deg})$, so, with the increase of distance of the goal the angle inclination of support leg increases, too especially of distance $28 \mathrm{~m}$ (55.8 deg) and after the distance increase the results of angle inclination of support leg, decrease up to $44 \mathrm{deg}$.

\section{Conclusion}

Based on the results of our study of correlations between the cinematic situational parameters for 30 free kicking instep analyzes executed by Cristiano Ronaldo, correlations significant positive relationships were shown with variable Number steps of ball approach - running stride - Ns and three other variables: Distance of the ball approach (running start) $-\mathrm{Da}, \mathrm{r}=0.431(\mathrm{p}=.020)$ and Length of the last step (Ls) - Ls, $r=0.397(\mathrm{p}=.033)$ and Angel inclination of support leg- $\phi, r=0.443(\mathrm{p}=0.018)$.

No significant difference was seen in correlation relationships between other variables, but by analyzing their results one can draw important relationships for practical work for trainers in soccer. So by comparing relationships between variable outcomes Angle of approach - $\alpha$ and Distance of free kick to the middle of the goal - Dg it looks like with the increase of the distance of free kick to the middle of the goal, the angle of approach increases $(19 \mathrm{~m}=17.5 \mathrm{deg}$,) to the distance $25 \mathrm{~m}$ (47 deg), and after that distance the angle of approach decreases $(26$ - $29=39.23 \mathrm{deg}, 30-38=37.14 \mathrm{deg}$ ). If relationships between compared the location of the execution site of free instep kick (Figure 3) with the goal scoring at the port (Figure 2), kicks in the same angle of the same side show that the angle of approach has value approximately $30 \mathrm{deg}$, whereas if the kicks happen $\mathrm{n}$ the opposite side, the angle of approach has the approximate value $50 \mathrm{deg}$ (for the right-footed players, as is our case study, Cristiano Ronaldo). Angle of approach, depending on forming a living wall as an inevitable obstacle to free kicks, remains to be studied in other research topics.

\section{Acknowledgements}

The authors thank the Institute for scientific research of the Faculty of Physical Education of Sport, University of Pristina, for technical assistance in analysis of video motion and statistical data processing.

\section{References}

[1] Kellis, E., \& Katis, A., 2007. Biomechanical characteristics and determinants of instep soccer kick. Journal of sports science \& medicine, 6, 154-165. [PubMed].

[2] Barfield, W. R., Kirkendall, D. T., \& Yu, B., 2002. Kinematic instep kicking differences between elite female and male soccer players. Journal of sports science \& medicine, 1 (3), 72 [PubMed].

[3] Meamarbashi, A., \& Hossaini, S., 2010. Application of Novel Inertial Technique to Compare the Kinematics and Kinetics of the Legs in the Soccer Instep Kick. Journal of Human Kinetics, 23, 5-13. [Google Scholar].

[4] Dörge, H. C., Bull-Andersen, T. B., Sørensen, H., and Simonsen, E. B., 2002. Biomechanical differences in soccer kicking with the preferred and the non- preferred leg. Journal of Sports Sciences, 20, 293-299. [PubMed].

[5] Isokawa, M., and A. Lees., 1988. A Biomechanical Analysis of the Instep Kick Motion in Soccer. In: Science and Football, Reilly, T., A. Lees, K. Davids and W. J. Murphy (Eds). E and FN Spon, London, pp: 449-455. [Google Scholar].

[6] Kellis, E., A. Katis and I. Gissis, 2004. Knee biomechanics of the support leg in soccer kicks from three angles of approach. Med. Sci. Sports Exerc., 36: 1017-1028. [PubMed].

[7] Reilly, T., \& Williams, A. M. (Eds)., 2003. Science and soccer. Routledge. [Google Scholar]. 
[8] Lees, A., Nolan, L., 2002. Three-Dimensional Kinematic Analysis of the Instep Kick Under Speed and Accuracy Conditions: Science and Football IV.: Spinks W., Reilly T., Murphy A., editors. London, Routledge; 16-21. [Google Scholar].

[9] Lees, A., \& Nolan, L., 1998. The biomechanics of soccer. Jurnal of sports science, 16 (3): 211 - 34. [PubMed].

[10] McLean, B. D., \& Tumilty, D. M., 1993. Left-right asymmetry in two types of soccer kick. British Journal of Sports Medicine, 27 (4), 260-262. [PubMed].

[11] Elliott, B., 2001. Biomechanics of Sport. In: Better Coaching: Advanced Coaches. [Google Scholar].

[12] Lees, A., 2002. Biomechanics Applied to Soccer Skills. In: Science and Soccer, Reilly, T. (Ed). E and FN Spon, London, ISBN: 978-0-203-41755-3, pp: 123-134. [Google Scholar].

[13] Lees, A., Asai, T., Andersen, T. B., Nunome, H., \& Sterzing, T., 2010. The biomechanics of kicking in soccer: A review. Journal of Sports Sciences, 28 (8), 805-817. [Google Scholar].

[14] Ismail, AR., Mansor, MRA., Ali, MFM., Jaafar, S., Makhtar, NK., 2010. Biomechanical Analysis of Ankle Force: A Case Study for Instep Kicking. Am J Appl Sci.; 7 (3): 323-330. [Google Scholar].

[15] Abo-Abdo, H. E., 1981. Kinematic and kinetic analysis of the soccer instepkick. Doctoral dissertation, Indiana University, Bloomington, IN. [Google Scholar].

[16] Barfield, B., 1998. The biomechanics of kicking in soccer. Clinics in Sports Medicine. 17 (4): 711-728. [PubMed].

[17] Tanaka, Y., Shiokawa, M., Yamashita, H., Tsuji, T., 2006.
Manipulability Analysis of Kicking Motion in Soccer Based on Human Physical Propertie. [Google Scholar].

[18] Opavsky, P., 2000. Biomechanical analysis of technical elements in football. Beograd: "Vizartis";. pp. 35-45. [Google Scholar].

[19] Asai, T., Carre, MJ., Akatsuka, T., Haake, SJ., 2005. The curve kick of a football I: impact with the foot. Sports Engineering, I.; 5: 183-192. [Google Scholar].

[20] Kapidžić, A., Huremović, T., Biberovic, A., 2014. Kinematic Analysis of the Instep Kick in Youth Soccer Players. Journal of Human Kinetics. volume 42, 81-90 DOI: 10.2478. [Google Scholar].

[21] Lees, A., Steward, I., Rahnama, N., \& Barton, G., 2009. Lower limb function in the maximal instep kick in soccer. Contemporary Sport, Leisure and Ergonomics. New York: Taylor \& Francis, 149-60. [Google Scholar].

[22] Kinovea -Kinovea. Setup. 0. 8. 15. exe, and Kinovea - 0. 8. 26 - win32.exe. (https://www.kinovea.org/).

[23] PhotoSuite 4 Platinum Editor from MGI Softwer. http://www.mgisoft.com and http://www.photosuite.com and http://www.sonic.net/mnitepub/pccafe/reviews/photosuite4/ph otosuite4.html.

[24] Soccer ball size $\mid$ Official football size chart, circumference \& weight. https://www.football-bible.com/soccer-info/soccerball-sizes.html.

[25] You Tube (Cristiano Ronaldo TOP 30 Free Kick Goals EVER. REAL MADRID FAN CLUB. https:// www.youtube.com/watch? $\mathrm{v}=\mathrm{aBfH} 280 \mathrm{OWek})$. 